\title{
Preparation of Samarium Doped Calcium Hydrogen Phosphate and Study of Its Density and Thermal and Dielectric Characteristics
}

\author{
K. K. Bamzai, Goldy Slathia, Bindu Raina, Rashmi Gupta, Seema Verma, \\ Shivani Suri, and Vishal Singh \\ Crystal Growth \& Materials Research Laboratory, Department of Physics and Electronics, University of Jammu, Jammu 180006, India \\ Correspondence should be addressed to K. K. Bamzai; kkbamz@yahoo.com
}

Received 31 December 2013; Accepted 13 February 2014; Published 24 March 2014

Academic Editors: N. P. Rajesh and K. Young

Copyright (C) 2014 K. K. Bamzai et al. This is an open access article distributed under the Creative Commons Attribution License, which permits unrestricted use, distribution, and reproduction in any medium, provided the original work is properly cited.

\begin{abstract}
Samarium doped calcium hydrogen phosphate was synthesized as single crystal by room temperature solution growth technique, namely, silica gel technique. The kinetics of the growth parameters was studied with regard to variation of $\mathrm{pH}$, dopant concentration, gel ageing, and upper reactant concentration. The optimum conditions for the growth of good quality single crystal were worked out. Single crystal X-ray diffraction analysis establishes that the crystal belongs to monoclinic system. The density observed by the flotation method is greater than the density of the reported pure calcium hydrogen phosphate thereby suggesting the incorporation of the dopant $(\mathrm{Sm})$ ion into the lattice of host (CHP). Thermal analysis gave two sharp endothermic peaks which are due to partial dehydration and phase transition, respectively. Dielectric studies establish a shift in the Curie temperature from 355 to $370^{\circ} \mathrm{C}$ only at higher frequencies thereby suggesting the relaxational behavior of the material.
\end{abstract}

\section{Introduction}

Rare earth phosphate crystals are interesting materials as they find wide technological applications on account of their ferroelectric, piezoelectric, optical, and other important properties whereas phosphoric acid serves as the base for the development of new class of materials. Calcium hydrogen phosphate dihydrate $\left[\mathrm{CaHPO}_{4} \cdot 2 \mathrm{H}_{2} \mathrm{O}\right]$, also known as Brushite minerals, is a stable form of calcium phosphate [1]. Recent studies used it as a precursor to form apatite $\left[\mathrm{Ca}_{10}\left(\mathrm{PO}_{4}\right)_{6}(\mathrm{OH})_{2}\right]$, an important bone forming mineral, as it contains $23 \%$ calcium in its anhydrous form. Brushite mineral has been found under various pathological conditions including kidney stones and some forms of arthritis [2, 3]. It was reported that the mineral deposits in the kidney contain various phases of calcium salts such as calcium oxalate and calcium phosphate [4]. Accordingly, it has been postulated that Brushite is a transient precursor for phases such as octacalcium phosphate and hydroxylapatite. Thus, calcium phosphate minerals are thought to be the initiator of stone formation in the kidney and/or bladder under favorable physiological environment. Brushite phase precipitates most readily in urine environments at $\mathrm{pH}$ less than 6.9 , so it has been postulated that Brushite enables the nucleation of calcium oxalate monohydrate (COM), the major component of kidney stones [5].

Recently in 2012 investigations of kidney stones obtained from some patients of India showed the concentration of ten elements, namely, $\mathrm{Ca}, \mathrm{Na}, \mathrm{K}, \mathrm{Mn}, \mathrm{Co}, \mathrm{Cr}, \mathrm{Zn}, \mathrm{Br}$, $\mathrm{Sm}$, and $\mathrm{Cl}[6]$ in the exploratory phase and a positive correlation was observed between calcium and most of the trace elements studied. So, going through the literature of calcium orthophosphates and finding the rare earth element samarium $(\mathrm{Sm})$ in kidney stones for the first time, it was thought worthwhile to make use of gel technique as a model to study the growth kinetics and influence of samarium on structural, morphological, and thermal properties of calcium hydrogen phosphate crystals. To the author's best knowledge there is no such report of the preparation and characterization of rare earth, that is, samarium doped calcium hydrogen phosphate. 


\section{Materials and Methods}

2.1. Materials Preparation. Samarium doped calcium hydrogen phosphate was prepared in the form of single crystal by reacting the constituent ions in the presence of silica gel by the process known as gel encapsulation technique. The gel used in the present investigation is sodium metasilicate and was prepared by adding $31.5 \mathrm{~g}$ of sodium metasilicate $\left(\mathrm{Na}_{2} \mathrm{SiO}_{3}\right.$ from s. d. Fine-Chem Ltd., 97\%) in 300 c.c. of distilled water so as to obtain a solution of $0.5 \mathrm{M}$ concentration. The sodium metasilicate solution was then left undisturbed for a few days and a clear solution was obtained on decantation. The solution was kept airtight to keep it away from contact with the atmosphere, thereby, avoiding absorption of $\mathrm{CO}_{2}$. The lower reactant was prepared by mixing a desired molarity solution of orthophosphoric acid $\left(\mathrm{H}_{3} \mathrm{PO}_{4}\right.$, from s. d. FineChem Ltd., 98\%) with sodium metasilicate solution. The upper reactant used consists of calcium chloride $\left(\mathrm{CaCl}_{2}\right.$ from s. d. Fine-Chem Ltd., 90.0\%) mixed with samarium nitrate $\left(\mathrm{Sm}\left(\mathrm{NO}_{3}\right)_{3} \cdot 6 \mathrm{H}_{2} \mathrm{O}\right.$ from s. d. Fine-Chem Ltd., 90.9\%) with $10 \%$ and $20 \%$ doping of Sm in calcium hydrogen phosphate. After setting of the gel for a certain time period, a mixture of samarium nitrate and calcium chloride in the ratio of $1: 1$ by volume was gently poured along the sides of the tube over the perfectly set gel ensuring that this process does not break gel. The supernatant ions $\left(\mathrm{Sm}^{3+}\right.$ and $\mathrm{Ca}^{2+}$ ) slowly diffused into the gel medium where it reacts with the lower reactant ions. As soon as the upper reactant comes in contact with the lower reactant, precipitates were formed instantaneously suggesting spontaneous nucleation. The expected chemical reaction is

$$
\begin{aligned}
& \mathrm{CaCl}_{2}+\mathrm{Sm}\left(\mathrm{NO}_{3}\right)_{3} \cdot 6 \mathrm{H}_{2} \mathrm{O}+2 \mathrm{H}_{3} \mathrm{PO}_{4} \\
& \longrightarrow\left(\mathrm{Sm}: \mathrm{CaHPO}_{4}\right) \cdot 2 \mathrm{H}_{2} \mathrm{O}+2 \mathrm{HCl}+3 \mathrm{HNO}_{3}+4 \mathrm{H}_{2} \mathrm{O}
\end{aligned}
$$

This precipitation band increases gradually in thickness as the diffusion proceeds into the gel. It was found that the growth of samarium doped calcium hydrogen phosphate dihydrate (abbreviated as Sm:CHPD) crystals is influenced by the initial Liesegang rings formation. The first clear ring was observed in $4 \mathrm{~h}$. The initial gel $\mathrm{pH}$ range 5-7 showed better formation of Liesegang rings which have promoted excellent crystal growth as observed in the present study (Figure 1(a)). Joshi et al. [2] discussed that as the number of Liesegang rings increased the initial rings tend to diffuse. The distance between two consecutive rings increased on moving toward the bottom of the test tubes. The Sm:CHPD crystals grew within the Liesegang rings within a period of two days. The Liesegang rings consist of insoluble precipitates of Sm:CHPD which are formed through diffusion of ions through the gel medium as seen in Figure 1(a). They could be polycrystalline in nature and could yield single crystals over the period of time. The single crystals then nucleate from this polycrystalline material and under suitable supersaturation condition they grow further which is evidenced from the disappearance of the Sm:CHPD precipitates. Figure 1(b) shows the same crystallizer after a period of five weeks; single crystals of Sm:CHPD of appreciable size appeared within

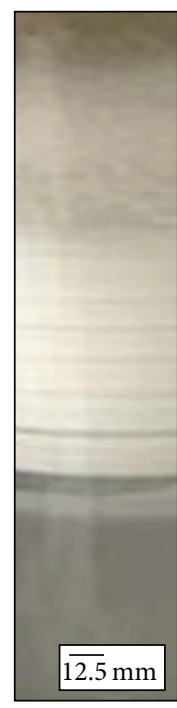

(a)

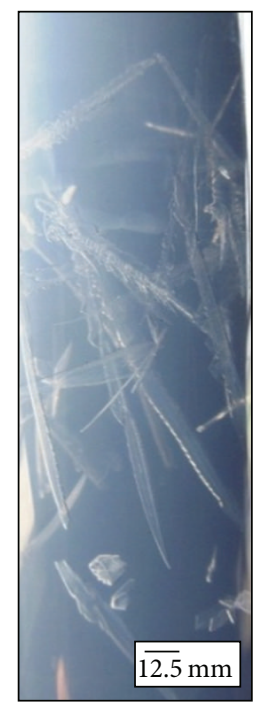

(b)
FIgURE 1: Photograph showing Liesegang rings and the growth of $\mathrm{Sm}: \mathrm{CHPD}$ crystals in silica gel at $\mathrm{pH} 7$.

the gel after the disappearance of the rings. The fully grown crystals were harvested by carefully washing the gel away from the crystals using distilled water. The harvested crystals as shown in Figure 2 were recovered from the solution by filtering through Whatman filter paper and air-dried for further measurements. From the results obtained it has been found that nucleation density is maximum for $1 \mathrm{M}$ of upper reactant concentration as compared to $0.5 \mathrm{M}$. This suggests that molarity plays an important role in the formation of crystals.

2.2. Characterization. The grown crystals of samarium doped calcium hydrogen phosphate (Sm:CHPD) were characterized for their structural, morphological, thermal, and dielectric studies. The morphological studies were carried out by the incident light microscope EPIGNOST manufactured by Carl Zeiss, Germany. Single crystal X-ray diffraction study was carried using single crystal Oxford X-ray diffractometer attached to CCD camera. The thermal behavior was investigated using differential scanning calorimetry (DSC) of Shimadzu make DSC-60 over a temperature range of 25$500^{\circ} \mathrm{C}$ in nitrogen atmosphere at a heating rate of $10^{\circ} \mathrm{C} / \mathrm{min}$. and flow rate of $30 \mathrm{~mL} / \mathrm{min}$. The dielectric studies were carried out with the help of automated impedance analyzer (4192A LF Model) interfaced with USB GPIB Converter 82357 B (Agilent) and further automated by using computer for data recording, storage, and analysis.

\section{Results and Discussion}

3.1. Kinetics of Growth. Different parameters such as gel aging time, concentration of reactants, and $\mathrm{pH}$ of the gel have the considerable effects on the growth rate. Various parameters varied during the present investigations to understated the growth kinetics is given as follows. 


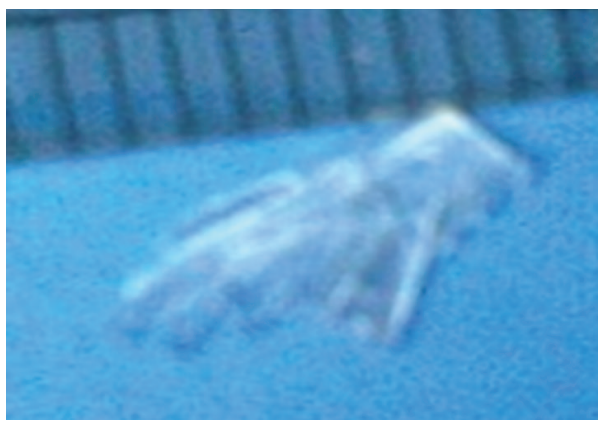

(a)

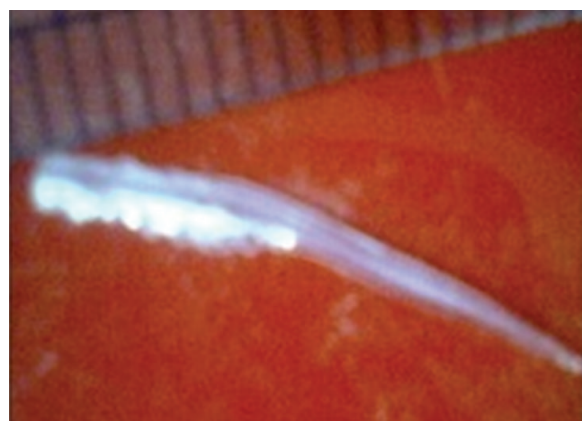

(b)

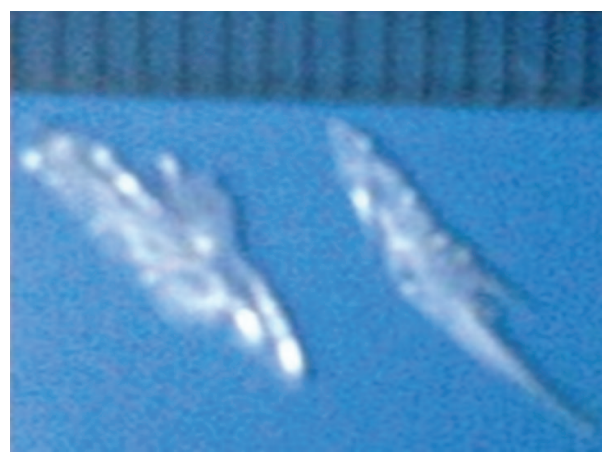

(c)

FIGURE 2: Single crystals of appreciable sizes with different morphologies.

3.1.1. Effect of PH of the Gel. The effect of gel $\mathrm{pH}$ (namely, $4,5,6$, and 7) was studied by keeping the upper and lower reactant concentration as $1 \mathrm{M}$ and $0.5 \mathrm{M}$, respectively. The $\mathrm{pH}$ 4 was not conducive for crystal growth. At $\mathrm{pH}$ values 5, 6, and 7, single crystals with different morphology were formed. However, at $\mathrm{pH} 5$ good quality single crystals were formed in the crystallizer. Liesegang rings were formed for $\mathrm{pH}$ values 5 and 7. Figure 3 illustrates the graph for number of nuclei formed versus time in case of different values of $\mathrm{pH}$. At each particular value of $\mathrm{pH}$, the number of nuclei formed increases with increase in time. However, it was observed that as the $\mathrm{pH}$ of gel is increased, the number of crystals decreases. Hence, in the present work $\mathrm{pH} 5$ is theoptimum condition for the growth of good quality Sm:CHPD single crystals.

3.1.2. Effect of Doping. The effect of doping on the growth of Sm:CHPD crystals was studied by taking the different doping concentrations, namely, $10 \%$ and $20 \%$, and keeping the other parameters like upper reactant concentration, lower reactant concentration, gel $\mathrm{pH}$, gel ageing, and gel concentration at $1 \mathrm{M}, 0.5 \mathrm{M}, 5,72 \mathrm{~h}$, and $0.5 \mathrm{M}$, respectively. It was observed that crystallization takes place at all doping concentrations and nucleation density is maximum for $20 \%$ and minimum for $10 \%$ doping. The crystals obtained were single crystals with different morphology.

3.1.3. Effect of Gel Ageing. Gels were allowed to age for different periods before adding the feed solutions. In the present work, to study the effects of gel ageing different gel ageing, that is, $24 \mathrm{~h}, 48 \mathrm{~h}, 72 \mathrm{~h}, 96 \mathrm{~h}$, and $120 \mathrm{~h}$, was used by keeping

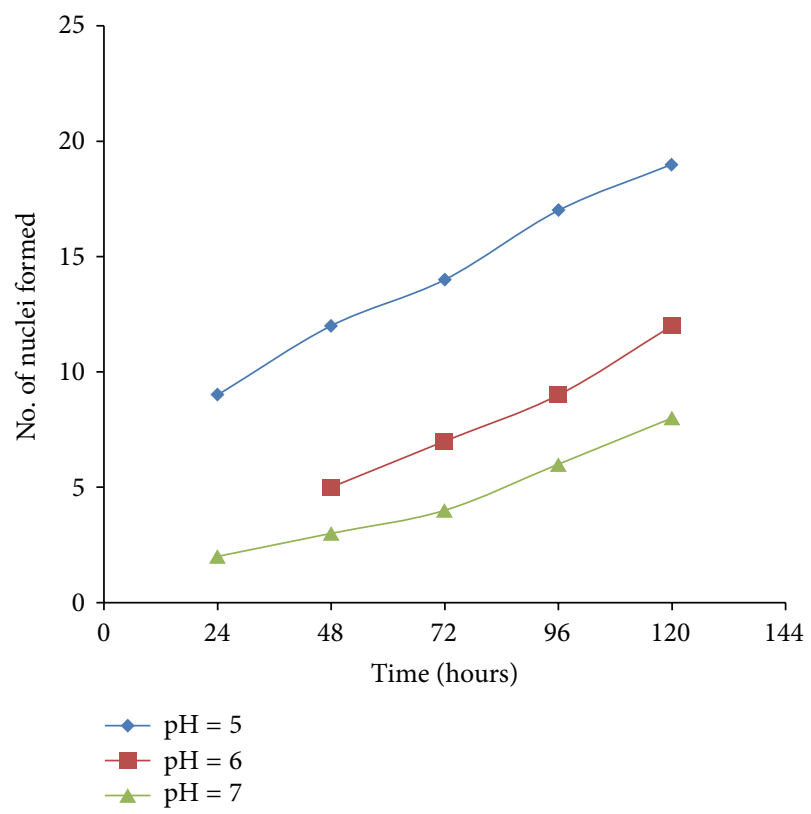

FIGURE 3: Graph showing number of nuclei formed versus time (in hrs).

gel concentration $0.5 \mathrm{M}$; upper reactant concentration $1 \mathrm{M}$; lower reactant concentration $0.5 \mathrm{M}$; and gel $\mathrm{pH}$ at 5 . Figure 4 shows the graph of number of crystals formed versus aging time of the gel. It was found that as the aging time of gel is increased the number of crystals decreased. However, gel 


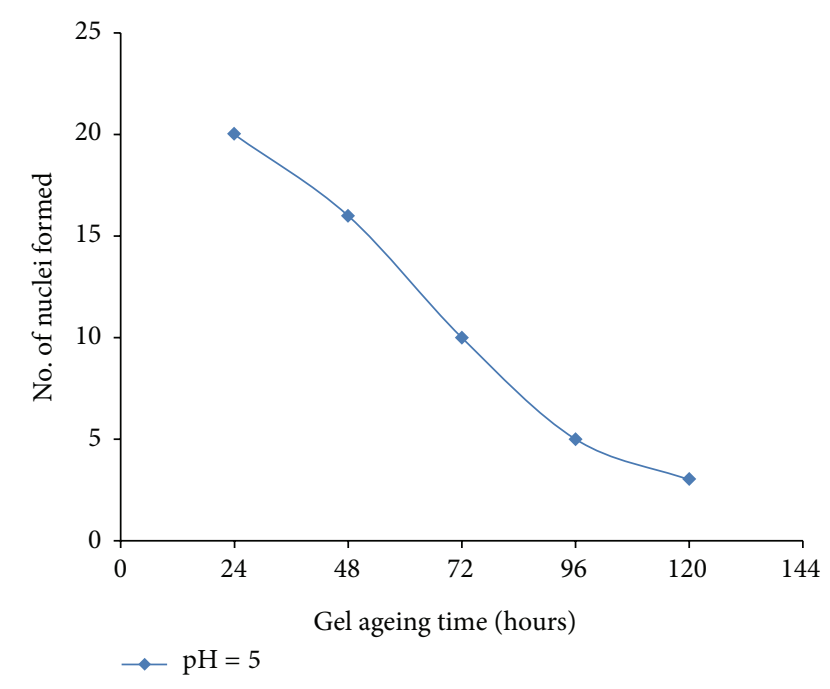

FIGURE 4: Graph showing number of nuclei formed versus gel ageing time.

aging has no pronounced effects on the size or quality of the crystals. In the present work, aging of $72 \mathrm{~h}$ was found suitable because it makes the gel neither dry/brittle nor fragile. Hence aging period of $72 \mathrm{~h}$ is the optimum condition for the growth of good quality Sm:CHPD single crystals.

3.1.4. Effect of Upper Reactant Concentration. To study the effect of variation of upper reactant concentration two concentrations of upper reactant, that is, $0.5 \mathrm{M}$ and $1 \mathrm{M}$, were taken keeping the lower reactant concentration as $0.5 \mathrm{M}$, gel concentration $0.5 \mathrm{M}$, and gel ageing $72 \mathrm{~h}$ and gel $\mathrm{pH}$ was kept at 5 . It was observed that good quality single crystals were grown in $1 \mathrm{M}$ concentration. Also nucleation takes place at all upper reactant concentrations and nucleation density is maximum at $1 \mathrm{M}$ and minimum at $0.5 \mathrm{M}$ of upper reactant concentration. Table 1 provides the summary of the effect of all these parameters on the growth of Sm:CHPD crystal. Based on the above experiments conducted by varying different parameters such as $\mathrm{pH}$ of the gel, concentration of reactants, gel aging time, and concentration of dopants, optimum conditions for the growth of samarium doped calcium hydrogen phosphate dihydrate crystals are given in the tabular form as Table 2.

3.2. Morphological and Structural Studies. The morphology of Sm:CHPD crystal was found to be typically in the form of thin platelets. Many are thin platelets of needle shape, blade shape with curved edges (Figure 2). The reason for different morphologies of crystals may be the variation of supersaturation of the solution at different depths (due to concentration gradient) within the gel medium. The optical microscopic photographs of surfaces of some Sm:CHPD crystals are shown in Figures 5 and 6. Figure 5 shows plane surfaces without any growth features except for some superficial defects. Microscopically examination showed the detailed morphology of these crystals. The growth of crystal is taking place mainly by spreading of layers and stacking of thin

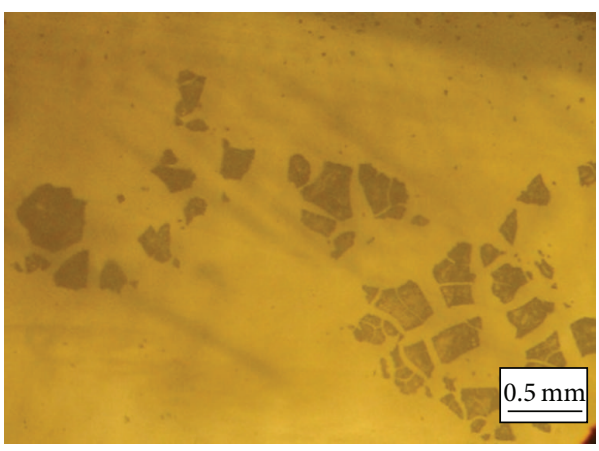

FIGURE 5: Optical micrograph of a typical crystal of Sm:CHPD showing plane surface without any growth features.

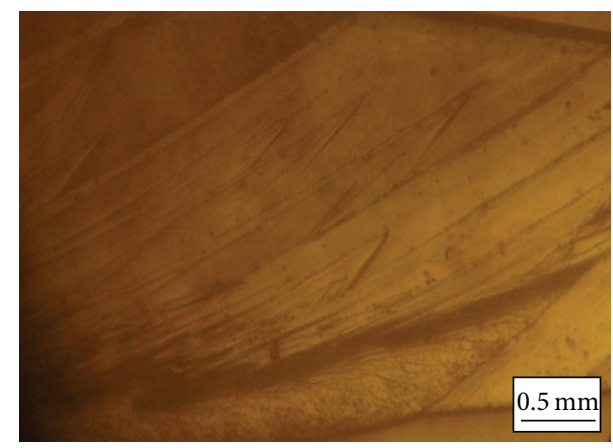

FIGURE 6: Optical micrograph of a typical crystal of Sm:CHPD showing the etch patterns.

platelets. These crystals are found to orient along the longer dimension of the parent crystal [7]. Figure 6 shows one of the observations on the surface of crystal where natural etch patterns were observed. The surface of the crystal appears to be strongly etched by the presence of channels and pores. The existence of natural etch pits suggests that the byproduct of the system causes the dissolution process during the growth of the crystal. The etch patterns confirm that the crystals are not free from dislocations. For structural investigation good quality single crystals were selected by examining them under microscope. The surfaces of the crystals were cleaned to remove any kind of gel impurity adhered to it. The lattice parameters obtained from the single crystal X-ray diffraction analysis in case of Sm:CHPD crystals are given in Table 3. The crystal was found to be monoclinic with space group C2/c. The space group indicates that the symmetry existing in the unit cell is " $c$ " glide perpendicular to twofold axis. The unit cell is base-centered (C) with two atoms per unit cell. The lattice parameters of Sm:CHPD is in agreement with already reported values of CHPD and Cd:CHPD [8] except that in case of Sm:CHPD there is a slight reduction in " $a$ " and " $b$ " axis and a slight elongation along " $c$ " axis. The ionic radii of Sm (0.96) are smaller than the host atom Ca (0.99), so the unit cell contraction takes place, which is also indicated by the decrease in volume of the unit cell. So, the addition of the dopants causes the distortion in the unit cell which results in contraction or expansion of the unit cell depending on 
TABLE 1: Summary of growth experiments based on variation of gel pH, dopant concentration, and gel ageing time in case of samarium doped calcium hydrogen phosphate (Sm:CHPD) crystals at a constant gel density of $1.04 \mathrm{~g} / \mathrm{cc}$.

\begin{tabular}{|c|c|c|c|c|}
\hline S. No. & Experiment & Constant parameter & Changing parameter & Results \\
\hline 1 & Variation of $\mathrm{pH}$ & $\begin{array}{l}\text { Upper reactant conc. } \\
(1 \mathrm{M}) \text {; lower reactant } \\
\text { conc. }(0.5 \mathrm{M}) \text {; gel } \\
\text { conc. }(0.5 \mathrm{M}) .\end{array}$ & Gel pH $(4,5,6,7)$ & $\begin{array}{l}\text { (1) Morphology } \\
\text { Single crystal, needle, thin platelets, blade shaped. } \\
\text { (2) Nucleation density } \\
\text { Minimum for pH } 7 \text { and maximum for pH } 5 \text {. } \\
\text { (3) pH value } 4 \text { is not conducive for crystal growth. } \\
\text { (4) Liesegang ring formation at pH } 5 \text { and } 7 \text {. }\end{array}$ \\
\hline 2 & $\begin{array}{l}\text { Variation of dopant } \\
\text { concentration }\end{array}$ & $\begin{array}{l}\text { Upper reactant conc. } \\
(1 \mathrm{M}) \text {; lower reactant } \\
\text { conc. }(0.5 \mathrm{M}) \text {; gel } \\
\text { conc. }(0.5 \mathrm{M}) \text {; gel } \\
\text { ageing time- } 72 \text { h; gel } \\
\text { pH } 5 .\end{array}$ & $\begin{array}{l}\text { Dopant concentration } \\
\quad(10 \% \text { and } 20 \%)\end{array}$ & $\begin{array}{l}\text { (1) Morphology } \\
\text { Single crystal, needle, thin platelets, blade shaped. } \\
\text { (2) Nucleation density } \\
\text { Minimum for } 10 \% \text { and maximum for } 20 \% \text {. } \\
\text { (3) Crystallization at all doping concentration. }\end{array}$ \\
\hline 3 & Variation of gel ageing & $\begin{array}{l}\text { Upper reactant conc. } \\
\text { (1 M); lower reactant } \\
\text { conc. }(0.5 \mathrm{M}) \text {; gel } \\
\text { conc. }(0.5 \mathrm{M}) \text {; gel pH } \\
5 .\end{array}$ & $\begin{array}{l}\text { Gel ageing }(24 \mathrm{~h}, 48 \mathrm{~h}, \\
72 \mathrm{~h}, 96 \mathrm{~h}, 120 \mathrm{~h})\end{array}$ & $\begin{array}{l}\text { (1) Morphology } \\
\text { Single crystal, needle, thin platelets, blade shaped. } \\
\text { (2) Nucleation density } \\
\text { Minimum for } 120 \mathrm{~h} \text { and maximum for } 24 \mathrm{~h} \text {. } \\
\text { (3) Crystallization at all ages. }\end{array}$ \\
\hline 4 & $\begin{array}{l}\text { Variation of upper } \\
\text { reactant } \\
\text { concentration }\end{array}$ & $\begin{array}{l}\text { Lower reactant conc. } \\
(0.5 \mathrm{M}) \text {; gel conc. } \\
(0.5 \mathrm{M}) \text {; gel } \mathrm{pH} 5 \text {; gel } \\
\text { ageing }(72 \mathrm{~h}) .\end{array}$ & $\begin{array}{c}\text { Upper reactant } \\
\text { concentration }(0.5 \mathrm{M} \\
\text { and } 1 \mathrm{M})\end{array}$ & $\begin{array}{l}\text { (1) Morphology } \\
\text { Single crystal, needle, thin platelets, blade shaped. } \\
\text { (2) Nucleation density } \\
\text { Minimum for } 0.5 \mathrm{M} \text { and maximum for } 1 \mathrm{M} \text { of upper } \\
\text { reactant concentration. } \\
\text { (3) Crystals nucleate at all upper reactant } \\
\text { concentrations. }\end{array}$ \\
\hline
\end{tabular}

TABLE 2: Optimum conditions for the growth of samarium doped calcium hydrogen phosphate (Sm:CHPD) crystals.

\begin{tabular}{lc}
\hline Conditions & Optimum value \\
\hline Density of sodium metasilicate solution & $1.04 \mathrm{gm} / \mathrm{cm}^{3}$ \\
Concentration of phosphoric acid & $0.5 \mathrm{M}$ \\
Concentration of calcium chloride & $0.9 \mathrm{M}$ \\
Concentration of samarium nitrate & $0.1 \mathrm{M}$ \\
$\mathrm{pH}$ of the gel & 5 \\
Gel ageing time & $72 \mathrm{hrs}$ \\
Temperature & Room temperature \\
Period of growth & 5 weeks \\
\hline
\end{tabular}

whether the ionic radii of dopants is smaller or greater than that of the host atom.

3.3. Density Determination. The density of the single crystal of Sm:CHPD was determined by the floatation method. In this method, two well miscible liquids were used. They were liquid bromine and distilled water. Liquid bromine of density $3.12 \mathrm{gm} / \mathrm{cc}$ was used as the denser liquid whereas distilled water of density $1 \mathrm{gm} / \mathrm{cc}$ was used as the less density liquid. The low density liquid was taken in a test tube. The transparent small size single crystal was put in the test tube. By the movement of the single crystal downward we concluded that the crystal density is higher than the test solution density. From that we added liquid bromine with a glass dropper until the crystal remained stationary in
TABLE 3: Lattice parameters for samarium doped calcium hydrogen phosphate (Sm:CHPD) crystals.

\begin{tabular}{lc}
\hline Lattice parameter & Sm:CHPD \\
\hline$a$ & $6.3554(9) \AA$ \\
$b$ & $15.1526(13) \AA$ \\
$c$ & $5.8098(6) \AA$ \\
$\alpha$ & $90^{\circ}$ \\
$\beta$ & $118.55^{\circ}$ \\
$\gamma$ & $90^{\circ}$ \\
volume, $V$ & $491.454 \AA^{3}$ \\
Space group & $\mathrm{C} 2 / \mathrm{c}$ \\
\hline
\end{tabular}

the middle of the solution. Then the density of the solution was determined by using specific gravity bottle of capacity $25 \mathrm{~mL}$ and an electric balance significant to four digits. The density of the crystal was calculated using the relation

$$
\rho=\frac{W_{3}-W_{1}}{W_{2}-W_{1}},
$$

where $W_{1}$ : weight of the empty specific gravity bottle, $W_{2}$ : weight of the gravity bottle with pure water, and $W_{3}$ : weight of the gravity bottle with solution.

The values obtained in the present case are given below.

Weight of the empty specific gravity bottle $-W_{1}=$ $17.4644 \mathrm{gm}$ 
Weight of the gravity bottle with pure water $-W_{2}=$ $42.1742 \mathrm{gm}$

Weight of the gravity bottle with solution $-W_{3}=$ $77.6511 \mathrm{gm}$

Density of the sample $(\rho)=2.43 \mathrm{gm} / \mathrm{cm}^{3}$

The known density of pure CHPD with monoclinic crystal system is $2.31 \mathrm{gm} / \mathrm{cm}^{3}$ [9]. The experimentally determined density of CHPD when doped with samarium comes to be $2.43 \mathrm{gm} / \mathrm{cm}^{3}$. This change in the density indicates the incorporation of impurity (Sm) in the crystal lattice of CHPD.

3.4. Thermal Behavior. The differential scanning calorimeter (DSC) curve for Sm:CHPD crystals is shown in Figure 7. As can be seen in figure, the curve shows two endothermic peaks, a broad one at around $163.4^{\circ} \mathrm{C}$ corresponding to the onset of evaporation of the hydration water and a welldefined peak at $189.4^{\circ} \mathrm{C}$ associated with a phase transition in the crystals. Further it has been reported $[10,11]$ that $25 \%$ of the hydrated water of CHPD is lost between 85 and $140^{\circ} \mathrm{C}, 50 \%$ between 115 and $170^{\circ} \mathrm{C}$, and total dehydration is achieved between 130 and $240^{\circ} \mathrm{C}$. Therefore, the peak at $163.4^{\circ} \mathrm{C}$ corresponds to partial dehydration (3) and the prominent peak at $189.4^{\circ} \mathrm{C}$ corresponds to total dehydration and monotite formation of Sm:CHPD (4). However, the thermograms of the CHPD crystal grown by Rajendran and Dale Keefe [12] show two endothermic peaks, a broad one at around $105^{\circ} \mathrm{C}$ corresponding to the onset of evaporation of the hydration water and a well-defined peak at $160^{\circ} \mathrm{C}$ associated with a phase transition in the crystals. So, the difference in the transition temperature of pure CHPD and $\mathrm{Sm}$ :CHPD suggests that the doping of rare earth element $\mathrm{Sm}$ has a pronounced effect on the thermal behavior of CHPD crystals thereby making the crystals thermally stable. Table 4 gives some of the important thermodynamical properties of Sm:CHPD:

$$
\begin{aligned}
\mathrm{Sm}: \mathrm{Ca}\left(\mathrm{HPO}_{4}\right) \cdot 2 \mathrm{H}_{2} \mathrm{O} \\
\longrightarrow\left(\text { heated between } 100 \text { and } 175^{\circ} \mathrm{C}\right) \mathrm{Sm}: \mathrm{Ca}\left(\mathrm{HPO}_{4}\right) \\
\cdot 2 \mathrm{H}_{2} \mathrm{O}+\mathrm{H}_{2} \mathrm{O}
\end{aligned}
$$

$$
\begin{aligned}
& \text { Sm : } \mathrm{Ca}\left(\mathrm{HPO}_{4}\right) \cdot \mathrm{H}_{2} \mathrm{O} \\
& \longrightarrow\left(\text { heated between } 175 \text { and } 210^{\circ} \mathrm{C}\right) \mathrm{Sm}: \mathrm{Ca}\left(\mathrm{HPO}_{4}\right) \\
& \quad+\mathrm{H}_{2} \mathrm{O}
\end{aligned}
$$

3.5. Electrical Characterization. The variation of dielectric constant with temperature at different frequencies of the applied a.c field ranging from $5 \mathrm{kHz}$ to $1 \mathrm{MHz}$ and in the temperature range from $30^{\circ} \mathrm{C}$ to $380^{\circ} \mathrm{C}$ is shown in Figure 8 . From the. variation of dielectric constant, the following points are noteworthy.

(1) The dielectric constant $\left(\varepsilon^{\prime}\right)$ of Sm:CHPD under the application of frequency varies little with temperature

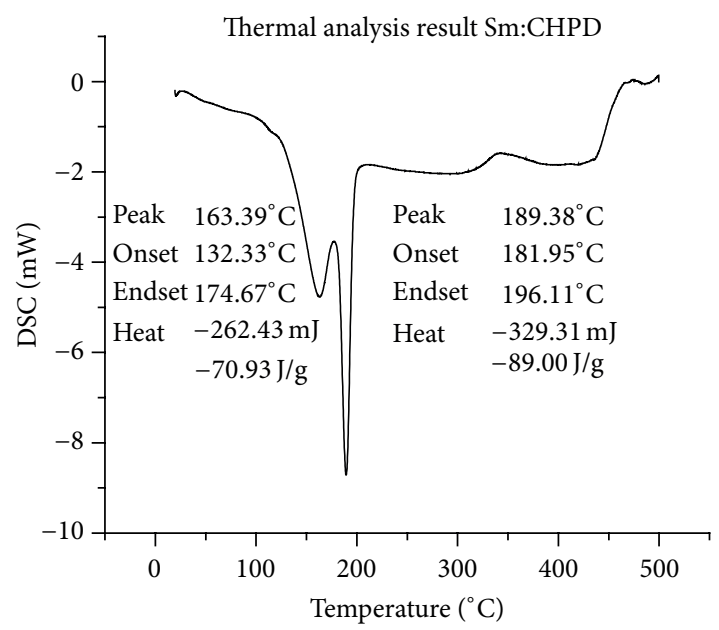

FIgURE 7: DSC plot depicting sharp endothermic peaks for Sm:CHPD crystal.

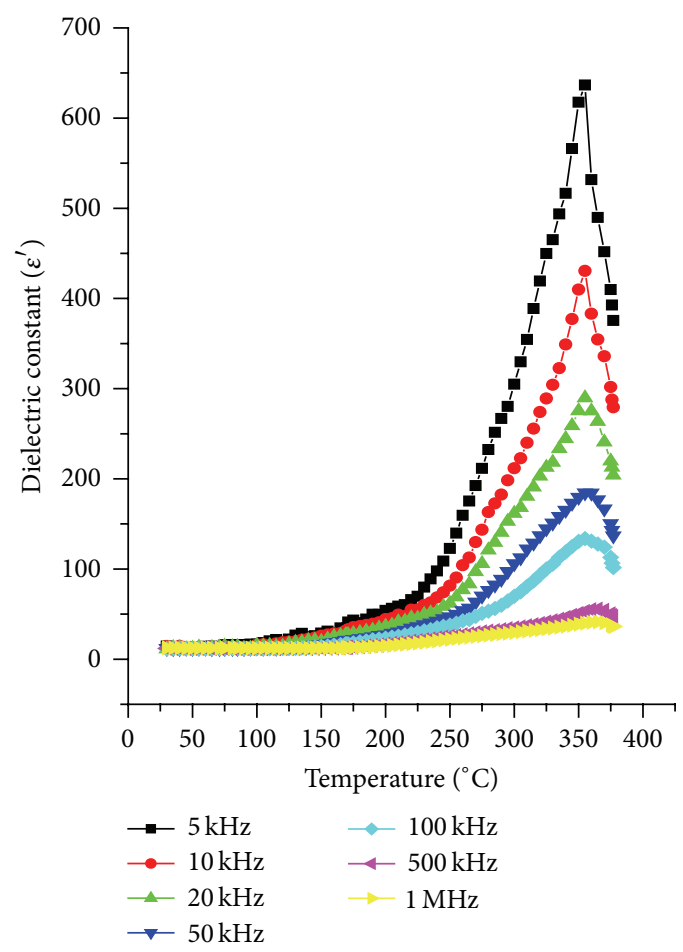

FIgURE 8: Variation of dielectric constant with temperature at different frequencies for Sm:CHPD.

up to $225^{\circ} \mathrm{C}$. As the temperature increases from 225 to $250^{\circ} \mathrm{C}$, the value of dielectric constant increases from 70 to 123 . Beyond $250^{\circ} \mathrm{C}$, the value of dielectric constant abruptly shoots up to a value of 637 at $355^{\circ} \mathrm{C}$ which is the maximum value, followed by a sudden fall up to 375 at $377^{\circ} \mathrm{C}$ at a lower frequency of $5 \mathrm{kHz}$.

(2) For other frequencies, that is, from $10 \mathrm{kHz}$ to $100 \mathrm{kHz}$, the peak value of dielectric constant observed is also at a temperature of $355^{\circ} \mathrm{C}$. Thus, $355^{\circ} \mathrm{C}$ is the transition 
TABLE 4: Differential scanning calorimetric (DSC) data of samarium doped calcium hydrogen phosphate (Sm:CHPD) crystal.

\begin{tabular}{lcccc}
\hline Sample & Weight of the sample $(\mathrm{mg})$ & Peaks & Enthalpy/heat flow $(\mathrm{mJ})$ & Transition temperature $\left({ }^{\circ} \mathrm{C}\right)$ \\
\hline \multirow{2}{*}{ Sm:CHPD } & \multirow{2}{*}{3.700} & I & -262.43 & 163.4 \\
& & II & -329.31 & 189.4 \\
\hline
\end{tabular}

temperature observed in case of Sm:CHPD for frequencies ranging from $10 \mathrm{kHz}$ to $100 \mathrm{kHz}$.

(3) For frequencies $500 \mathrm{kHz}$ and $1 \mathrm{MHz}$, the value of transition temperature shifts towards higher temperature $\left(370^{\circ} \mathrm{C}\right)$ thereby indicating relaxational behavior of the material for higher frequencies.

The variation of dielectric constant as a function of frequency at different temperatures is shown in Figure 9. It can be seen from the figure that the values of dielectric constant decrease continuously with increasing frequency. This decrease in the value of dielectric constant with increasing frequency is a normal dielectric behaviour. This type of behaviour has been reported by many investigators [13-15]. From the graph, following points may be noted.

(1) The value of dielectric constant at room temperature, that is, $30^{\circ} \mathrm{C}$, is 15 at $5 \mathrm{kHz}$. As the frequency increases from $5 \mathrm{kHz}$ to $1 \mathrm{MHz}$, the values of dielectric constant go on decreasing and its value becomes 12 at a frequency of $1 \mathrm{MHz}$.

(2) At other temperatures, that is, 50,100, 150, and $200^{\circ} \mathrm{C}$, the values of dielectric constant show the same decreasing trend with the increase in frequency from $5 \mathrm{kHz}$ to $20 \mathrm{kHz}$ after which it attains saturation, thereby exhibiting a normal dielectric behavior.

(3) At each particular temperature, the dielectric constant has a maximum value at lowest frequency, that is, $5 \mathrm{kHz}$, with maximum (637) being for a temperature of $355^{\circ} \mathrm{C}$.

\section{Conclusions}

From the results obtained on samarium doped calcium hydrogen phosphate crystals, one can draw the following broad conclusions.

(i) Rare earth (samarium) doped calcium hydrogen phosphate dihydrate (Sm:CHPD) has been successfully synthesized in the laboratory by room temperature solution technique, that is, gel encapsulation technique.

(ii) Single crystal X-ray diffraction results reveal that the grown crystals have monoclinic system with lattice parameters: $a=6.3554(9) \AA, b=15.1526(13) \AA, c=$ 5.8098(6) $\AA$, $\alpha=90^{\circ}, \beta=118.55^{\circ}$, and $\gamma=90^{\circ}$ with volume $V=491.454(\AA)^{3}$ and space group $\mathrm{C} 2 / \mathrm{c}$. Comparison of lattice parameters of grown crystals with those of already reported pure calcium hydrogen phosphates suggests that the doping of rare earth element has no effects on the crystal structure of

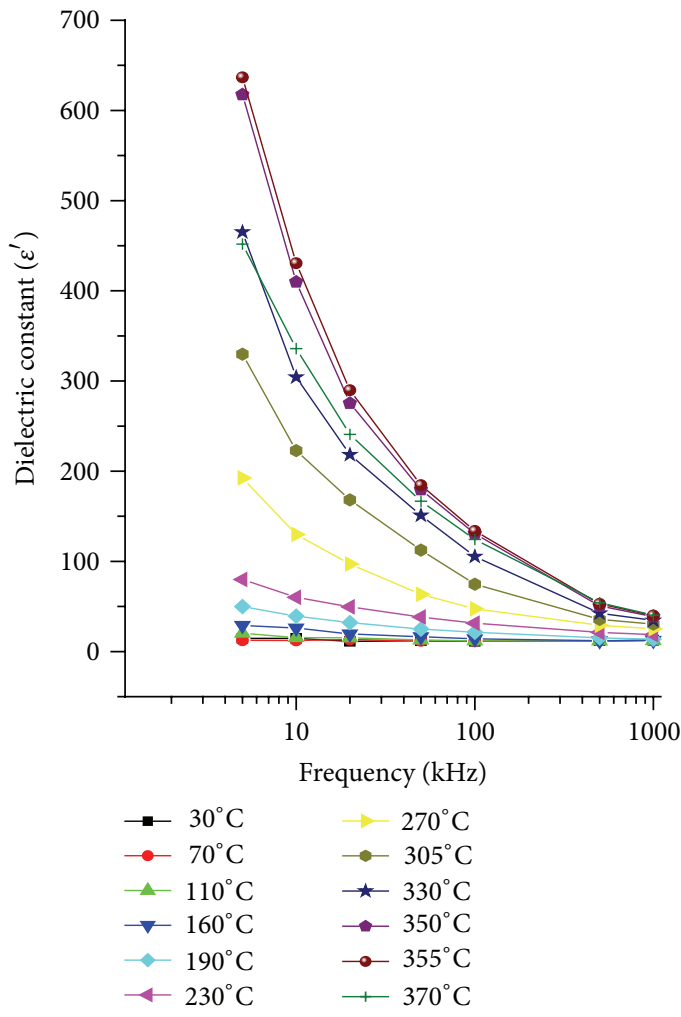

FIGURE 9: Variation of dielectric constant with frequency at different temperatures for Sm:CHPD.

the host rather the unit cell contraction has taken place indicated by decrease in its volume.

(iii) Surface morphology shows that single crystals have smooth faces with thin growth layers. The growth has taken place mainly by spreading of layers and stacking of thin platelets. The natural etch patterns confirm the dissolution process to be taking place during growth of crystals.

(iv) Density of the grown crystal determined by flotation method comes to be $2.43 \mathrm{gm} / \mathrm{cm}^{3}$ which are greater than the density of reported pure CHP. The change in density values is due to incorporation of dopant $(\mathrm{Sm})$ into the lattice of host (CHP).

(v) Thermal results show the occurrence of two sharp endothermic peaks in DSC curve at temperatures of $163.4^{\circ} \mathrm{C}$ and $189.4^{\circ} \mathrm{C}$. The peak at $163.4^{\circ} \mathrm{C}$ is related to partial dehydration whereas the peak at $189.4^{\circ} \mathrm{C}$ corresponds to total dehydration and monotite formation which is considered to be the phase transition of the material. No glass transition is found in the thermal 
analysis of the grown material which confirms the crystallinity of the material.

(vi) The dielectric constant is strongly temperature and frequency dependent. The dielectric constant shows a peak at $355^{\circ} \mathrm{C}$ for all values of frequency ranging from $5 \mathrm{kHz}$ to $100 \mathrm{kHz}$. For frequencies $500 \mathrm{kHz}$ and $1 \mathrm{MHz}$, the value of transition temperature shifts towards higher temperature $\left(370^{\circ} \mathrm{C}\right)$ thereby indicating relaxational behavior of the material for higher frequencies. Thus, in case of Sm:CHPD there are two different transition peaks which suggest that material is exhibiting a typical relaxor behavior and hence this material is suggested to be a relaxor ferroelectric.

\section{Conflict of Interests}

The authors declare that there is no conflict of interests regarding the publication of this paper.

\section{References}

[1] V. S. Joshi and M. J. Joshi, "FTIR spectroscopic, thermal and growth morphological studies of calcium hydrogen phosphate dihydrate crystals," Crystal Research and Technology, vol. 38, no. 9, pp. 817-821, 2003.

[2] V. S. Joshi, B. B. Parekh, M. J. Joshi, and A. B. Vaidya, "Herbal extracts of Tribulus terrestris and Bergenia ligulata inhibit growth of calcium oxalate monohydrate crystals in vitro," Journal of Crystal Growth, vol. 275, no. 1-2, pp. 1403-1408, 2005.

[3] V. S. Joshi, B. B. Parekh, M. J. Joshi, and A. D. B. Vaidya, "Inhibition of the growth of urinary calcium hydrogen phosphate dihydrate crystals with aqueous extracts of Tribulus terrestris and Bergenia ligulata," Urological Research, vol. 33, no. 2, pp. 8086, 2005.

[4] K. C. Joseph, B. B. Parekh, and M. J. Joshi, "Inhibition of growth of urinary type calcium hydrogen phosphate dihydrate crystals by tartaric acid and tamarind," Current Science, vol. 88, no. 8 , pp. 1232-1238, 2005.

[5] D. R. Basavaraj, C. S. Biyani, A. J. Browning, and J. J. Cartledge, "The role of urinary kidney stone inhibitors and promoters in the pathogenesis of calcium containing renal stones," $E A U-E B U$ Update Series, vol. 5, no. 3, pp. 126-136, 2007.

[6] A. Shrivastava, Annual Report of UGC-DAE Consortium for Scientific Research University Campus, 17, Indore (2011-2012).

[7] M. Rak, N. N. Eremin, T. A. Eremina et al., "On the mechanism of impurity influence on growth kinetics and surface morphology of KDP crystals. I. Defect centres formed by bivalent and trivalent impurity ions incorporated in KDP structuretheoretical study," Journal of Crystal Growth, vol. 273, no. 3-4, pp. 577-585, 2005.

[8] K. K. Bamzai, S. Suri, and V. Singh, "Synthesis, characterization, thermal and dielectric properties of pure and cadmium doped calcium hydrogen phosphate," Materials Chemistry and Physics, vol. 135, pp. 158-167, 2012.

[9] V. S. Dorozhkin, "Nanodimensional and nanocrystalline calcium orthophosphates," The American Journal of Biomedical Engineering, vol. 2, pp. 48-97, 2012.

[10] G. Berend and A. J. Hegedüs, "Thermoanalytische untersuchung von sekundarem calcium phosphatidihydrat," Thermochimica Acta, vol. 11, pp. 367-379, 1975.
[11] F. Tamimi-Mariño, J. Mastio, C. Rueda, L. Blanco, and E. López-Cabarcos, "Increase of the final setting time of brushite cements by using chondroitin 4-sulfate and silica gel," Journal of Materials Science: Materials in Medicine, vol. 18, no. 6, pp. 11951201, 2007.

[12] K. Rajendran and C. Dale Keefe, "Growth and characterization of calcium hydrogen phosphate dihydrate crystals from single diffusion gel technique," Crystal Research and Technology, vol. 45, no. 9, pp. 939-945, 2010.

[13] G. E. Pike, "ac conductivity of scandium oxide and a new hopping model for conductivity," Physical Review B, vol. 6, no. 4, pp. 1572-1580, 1972.

[14] S. K. Arora, V. Patel, R. G. Patel, B. Amin, and A. Kothari, "Electrical characterization of strontium tartrate single crystals," Journal of Physics and Chemistry of Solids, vol. 65, no. 5, pp. 965-973, 2004.

[15] E. D. Politova, V. V. Ivanova, G. M. Kaleva et al., "Dielectric and piezoelectric properties of the lead-based perovskite ceramics," Ferroelectrics, vol. 313, pp. 129-133, 2004. 

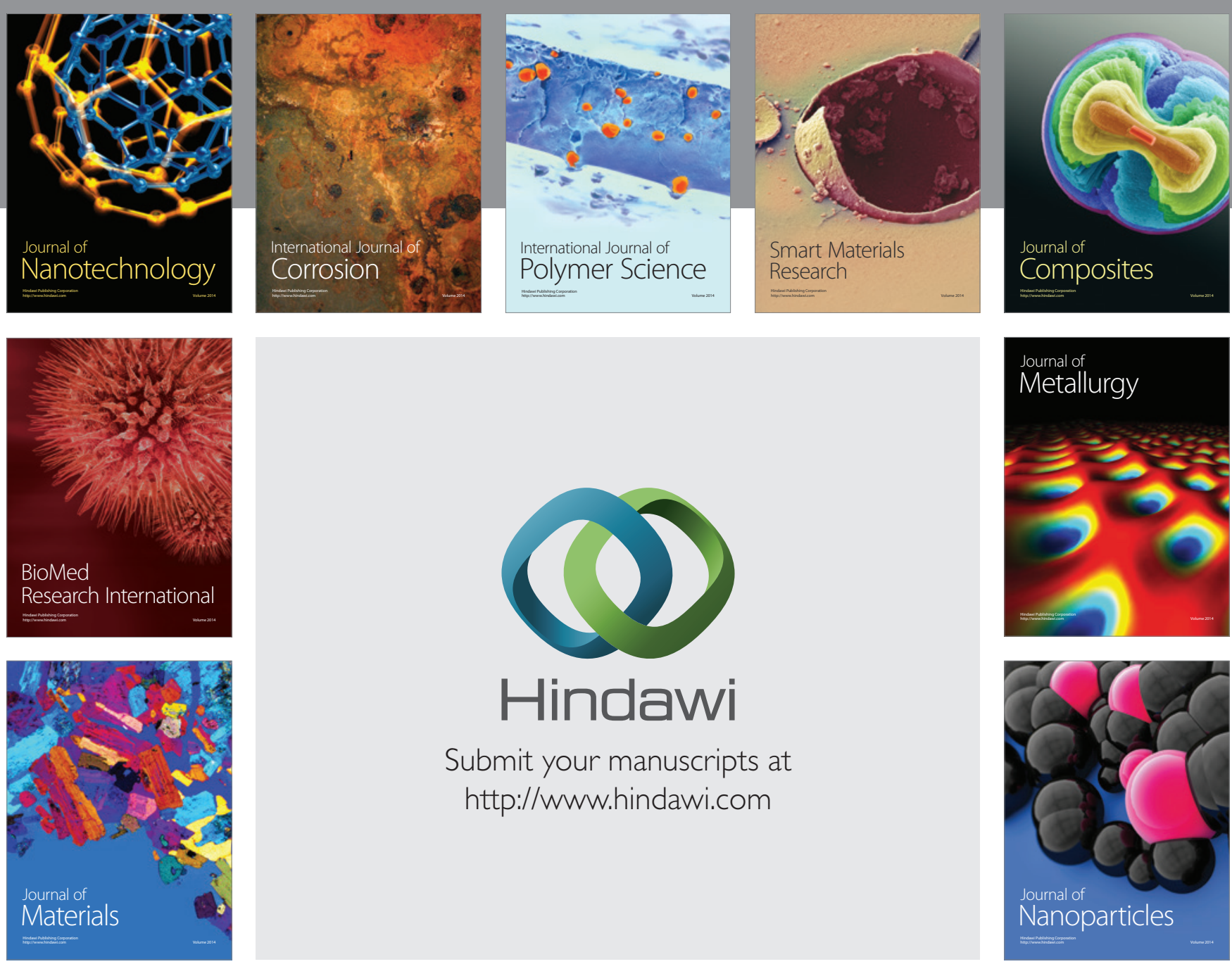

Submit your manuscripts at http://www.hindawi.com
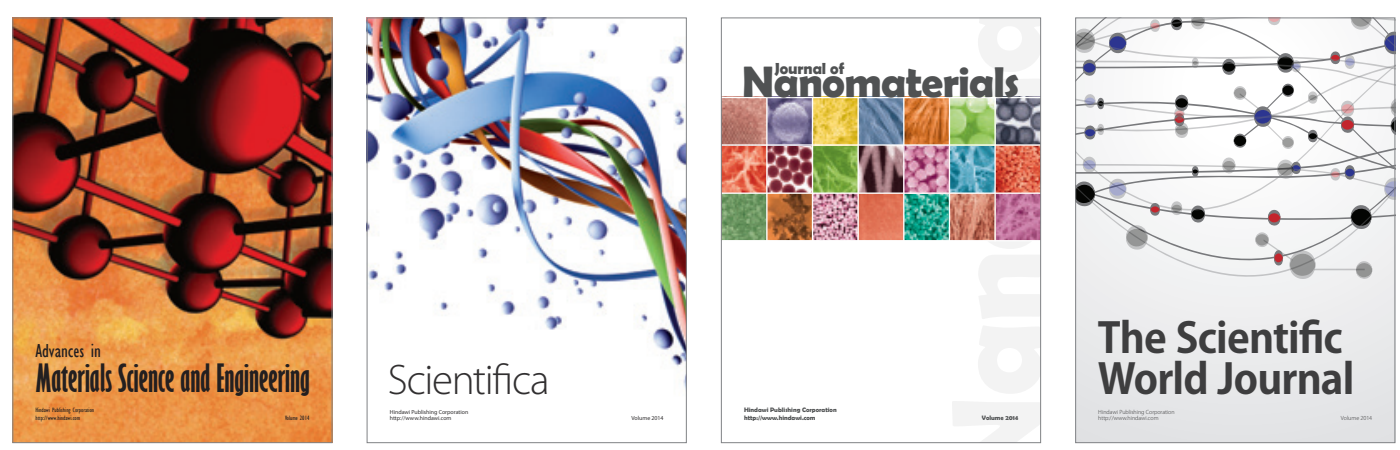

\section{The Scientific World Journal}
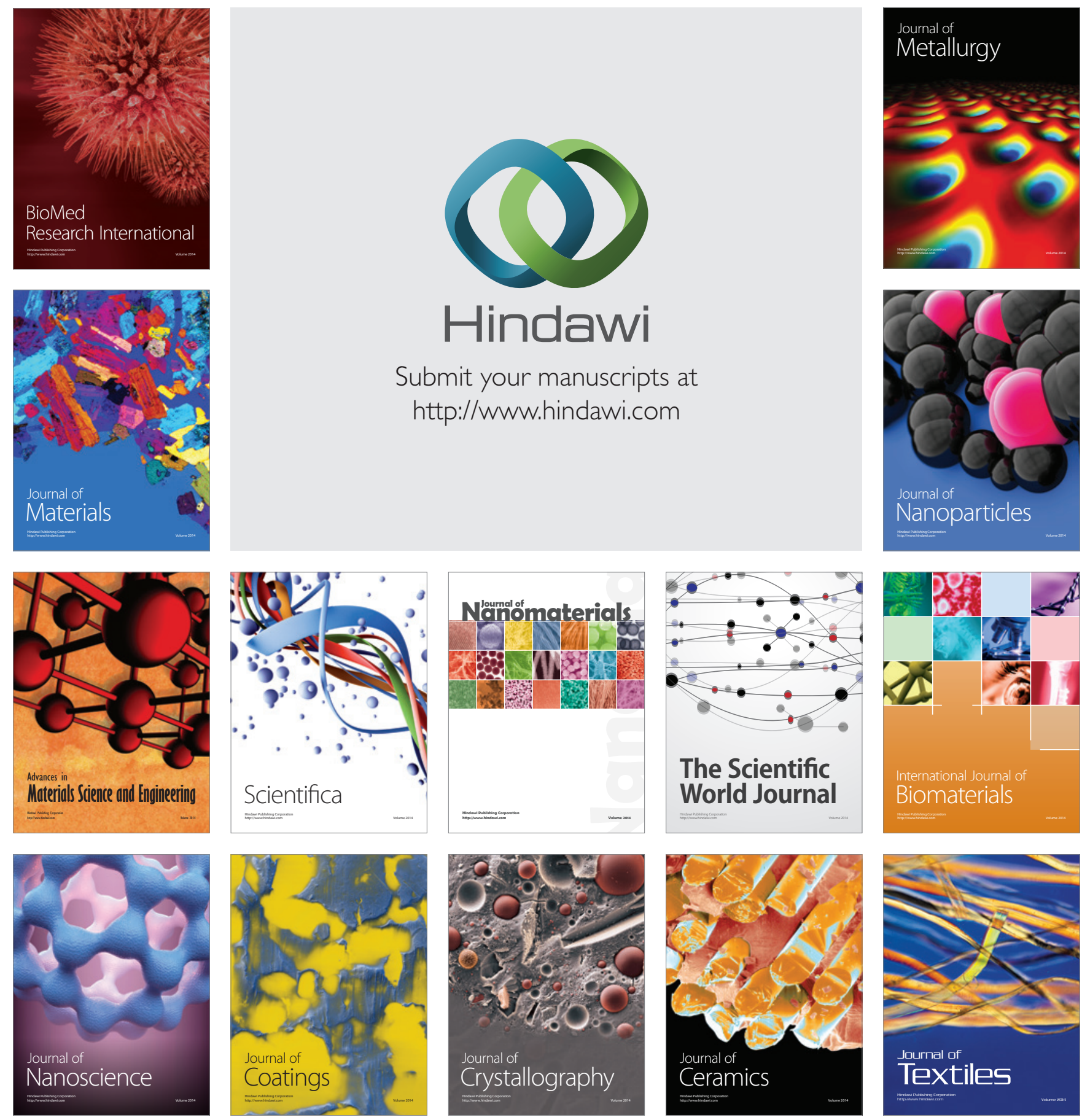